Marta Zalewska-Zacharek, Jolanta Zegarska@, Lena Nowak-Łoś@, Magdalena Kuligowska-Prusińska®, Grażyna Odrowąż-Sypniewska®, Marek Grabiec®, Karina Chmielarz®

Nicolaus Copernicus University in Torun, Collegium Medicum in Bydgoszcz, Bydgoszcz, Poland

\title{
The assessment of usefulness of HE4 and CA125 quantification for the diagnostics of endometrial cancer
}

\author{
Corresponding author: \\ Karina Chmielarz, Nicolaus \\ Copernicus University in Torun, \\ Collegium Medicum in Bydgoszcz, \\ Bydgoszcz, Poland \\ e-mail: karina.chmielarz@gmail.com
}

Medical Research Journal 2019; Volume 4, Number 4, 201-209 10.5603/MRJ.a2019.0036 Copyright (C) 2019 Via Medica ISSN 2451-2591

\begin{abstract}
Endometrial cancer is one of the most prevalent uterine malignancies. This disease occurs mostly in older women, frequently affected with other comorbidities. Hence, it is important to search for novel, less burdensome diagnostic modalities, enabling the objective assessment of the patient's status and facilitating qualification to relevant risk groups prior to surgical treatment. The aim of this study was to verify the usefulness of CA125 and HE4 in the evaluation of endometrial cancer. The study included 308 women treated at University Hospital No. 2 in Bydgoszcz. The study group included 180 patients operated due to endometrial cancer. The control group included 128 women operated due to perineal statics disorders. The concentrations of tumour markers were measured with ELISA-based ready-to-use diagnostic kits.

Patients with endometrial cancer and healthy women differed significantly in terms of HE4 concentrations $(P=0.001)$. The serum concentration of HE4 in stage I endometrial cancer patients was significantly higher $(\mathrm{Me}=88.37 \mathrm{pM})$ than in healthy women $(\mathrm{Me}=46.14)(\mathrm{P}=0.007)$. The analysis of ROC curves with the determination of the area under curve showed $66.7 \%$ sensitivity and 78.1\% specificity of HE4. AUC for HE4 amounted to 0.721 and was the highest of all markers. Our analysis revealed that HE4 is useful in the detection of endometrial cancer, while Human Epididymis Protein 4 can potentially be used for screening purposes. CA125 antigen, previously used in the diagnostic process, is useless or may possess limited usefulness. There is a need for further studies on larger populations of female patients.
\end{abstract}

Key words: endometrial cancer; endometrial carcinoma; HE4; CA125; biomarkers; tumour; diagnostics Med Res J 2019; 4 (4): 201-209

\section{Introduction}

Endometrial cancer is one of the most common uterine malignancies. It is the sixth most common cancer in women in the world [1]. The incidence of endometrial cancer is higher in countries with high economic status, as compared with poorer countries. In the United States, the incidence rate is $42 / 100 \mathrm{k} / \mathrm{year}$, while in Western Europe the incidence rate is $34 / 100 \mathrm{k} /$ year. The occurrences in people above 45 years of age represent more than $90 \%$ of the cases and are cumulated mainly in two peaks: at 54-59 and 65-70 years of age [2, 3]. It has been observed that the disease develops in an increasing number of young women of reproductive age (5-8\% of patients). Recent studies suggest an increase in the number of deaths due to endometrial cancer, despite a significant decline in mortality rates observed to date [4].

Up to $90 \%$ of cases of endometrial cancer are characterised by early onset of symptoms, which allows an early diagnosis of the disease [5]. The diagnostics allowing the identification of the disease are based on histopathological analysis of the material obtained via fractional curettage of the uterine cavity and the cervical canal or via endoscopic methods. Due to the presence of the tumour mainly in elderly women, often burdened with additional diseases, it is important to seek less invasive diagnostic techniques. Determining new, highly sensitive, and specific tumour markers appears to be one such method.

The markers known to date cannot be routinely used in the diagnostics of uterine cancer due to their 
relatively low sensitivity and specificity, and the predictive value of the tests that allow the quantification of these substances.

The proportion of cases of operable stage 1 endometrial cancer is $75 \%$. However, $20-30 \%$ of patients classified to FIGO (International Federation of Gynaecology and Obstetrics) stage 1 are at high or medium risk of relapse related with infiltration of the uterine muscle, invasion of lymphatic vessels, and a high degree of differentiation $[8,9]$. This group of patients may benefit most from markers that permit detection of early relapse and monitoring the response to the treatment used. At the same time, a sufficiently sensitive and specific marker can be used as a prognostic indicator before the planned surgical intervention in order to ensure the proper therapeutic decisions.

It is important to search for a tumour marker to be used for screening in women at high risk of endometrial cancer, including those with Lynch II syndrome or the PTEN gene defect, as well as patients treated with tamoxifen or obese patients with diabetes. A sensitive marker is essential in the monitoring of patients with a high risk of relapse or a systemic form of endometrial cancer. Currently, the monitoring of patients after and during treatment is based mainly on the clinical assessment of symptoms and diagnostic imaging, which results in a late diagnosis of an already advanced disease [10].

Studies published to date suggest an increased expression of HE4 in endometrial cancer [11-13]. Moore, R.G et al. reported that the HE4 concentration is increased at all stages of endometrial cancer and is characterised by higher sensitivity in the detection of the tumour compared to CA125 (78.7\% vs. $67.1 \%)$ [12-13]. Therefore, the aim of this study was to evaluate the suitability of the quantification of the tumour markers HE4 and CA125 for the diagnostics of endometrial cancer.

\section{Material and methods}

Permission to conduct this study was obtained from the Bioethics Committee of the Ludwik Rydygier Collegium Medicum of Nicolaus Copernicus University in Toruń (no. KB/248/2010).

\section{Study design and subjects}

The study included 308 women who were patients in the Clinic of Obstetrics, Gynaecological Diseases, and Oncological Gynaecology of the J. Biziel University Hospital no. 2 in Bydgoszcz in 2010-2011. Included were only postmenopausal women with the last menstrual period at least one year prior to the study.
The patients for each group were recruited separately. The patients were divided into two groups. The study group consisted of 180 patients operated due to endometrial cancer diagnosed preoperatively in a histopathological examination. The control group consisted of 128 women operated due to perineal statics disorders. The diagnosis was based on a histopathological examination performed at the Institute of Pathomorphology of the J. Biziel University Hospital no. 2 in Bydgoszcz. The mean age of the patients diagnosed with cancer was 61 years $(S D=10.8)$, while the mean age of the patients from the control group was 61 years $(S D=9.5)$.

All women included in the study underwent a medical history, gynaecological examination with rectal examination, and ultrasound examination.

Medical history concerned the age, the date of the first and the last menstruation, the number of pregnancies and deliveries, the occurrence of chronic diseases (diabetes, hypertension, cancer), and drugs (tamoxifen). The gynaecological examination included cytology, speculum examination, and bimanual pelvic examination. Ultrasonography was performed using standard transvaginal probes with a frequency range of 5-9 $\mathrm{MHz}$.

Body mass index (BMI) was calculated based on the formula: $\mathrm{BMI}=$ weight $[\mathrm{kg}] /$ height $\left[\mathrm{m}^{2}\right]$

Hypertension was diagnosed when the value of systolic blood pressure was above $140 \mathrm{mmHg}$ and the value of diastolic blood pressure was above $90 \mathrm{mmHg}$ (as defined by the World Health Organisation).

Clinical diagnosis was based on histopathological examination of uterine cavities that were performed at the Department of Pathomorphology of the J. Biziel University Hospital no. 2 in Bydgoszcz.

Statistical analyses did not reveal any statistically significant differences between the compared groups.

\section{Blood sampling}

The examined material was blood serum obtained from fasting patients preoperatively by basilic vein puncture. A volume of $10 \mathrm{ml}$ was collected into sterile glass tubes without anticoagulant. In order to obtain blood serum, blood samples were centrifuged for 10 minutes at about 1500 ' $\mathrm{g}$. The obtained sera were stored at $-80^{\circ} \mathrm{C}$ until the determination of markers was performed.

\section{Methods and statistical analysis}

The concentration of HE4 and CA125 in the blood serum of the women were determined using ready-touse ELISA test kits based on a sandwich immunoenzymatic system.

To determine the serum concentration of HE4, we used the HE4 EIA test from FUJIREBIO Diagnostics, Inc. (Gothenburg, Sweden), with a range of detection 
of 15-900 pM. CA125 was quantified using ELISA tests from Demeditec Diagnostics GmbH (Kiel, Germany) with a range of detection of $0-500 \mathrm{U} / \mathrm{ml}$.

\section{Statistical analysis}

Statistical analysis was performed using the statistical software STATISTICA 9.1 from StatSoft ${ }^{\circledR}$ and employed Shapiro-Wilk normality test and Student's t-test for independent quantitative variables with a distribution similar to normal. Other variables were assessed using the Mann-Whitney $U$ test. The analysis of the qualitative variables was performed using the nonparametric chi-square test, and the results were presented in a contingency table with percentages calculated by columns. Differences at a significance concentration $\mathrm{P}<0.05$ were considered as statistically significant and marked. Multidimensional dependencies were shown in logistic regression models using independent variables of a dichotomous nature that were determined based on the cut-off values estimated in ROC analysis. The assessment of the diagnostic accuracy of the tumour markers was conducted on the basis of the producer's reference values and our own data, including the $95 \%$ confidence interval of the arithmetic mean $(95 \% \mathrm{Cl})$. The sensitivity, specificity, positive predictive value (PPV), negative predictive value (NPV), and accuracy of the method were established. The presented ROC charts including the area under the curve (AUC) also proved helpful in the assessment of the diagnostic suitability of the markers.

\section{Results}

The patients were divided into two groups. The characteristics of the investigated groups are given in Table 1.

Table 1. Characteristics of the study groups

\begin{tabular}{lcc}
\hline & $\begin{array}{l}\text { Cancer } \\
\mathbf{N}=180 \\
{[\mathbf{M} \pm \mathbf{S D}]}\end{array}$ & $\begin{array}{l}\text { Control Group } \\
\mathbf{N = 1 2 8} \\
{[\mathbf{M} \pm \mathbf{S D}]}\end{array}$ \\
\hline $\begin{array}{l}\text { Age } \\
\text { (years) }\end{array}$ & $61.1 \pm 10.8$ & $61.4 \pm 9.5$ \\
$\begin{array}{l}\text { FM } \\
\text { (age) }\end{array}$ & $13.8 \pm 1.7$ & $14.1 \pm 1.8$ \\
$\begin{array}{l}\text { LM } \\
\text { (age) }\end{array}$ & $49.8 \pm 3.1$ & $50.0 \pm 3.1$ \\
$\begin{array}{l}\text { BMI } \\
\text { (kg/m }{ }^{2} \text { ) }\end{array}$ & $30.0 \pm 6.1$ & $28.6 \pm 4.8$ \\
$\begin{array}{l}\text { Number of } \\
\text { pregnancies }\end{array}$ & $2.5 \pm 1.3$ & $2.8 \pm 1.4$ \\
$\begin{array}{l}\text { Number of births } \\
\text { M - mean; SD - standard deviation; FM - first menstruation; LM - }\end{array}$ & $2.2 \pm 1.2$ & $2.6 \pm 1.4$ \\
last menstruation
\end{tabular}

The mean age of the patients diagnosed with cancer was 61 years $(S D=10.8)$, while the mean age of the patients from the control group was 61 years $(S D=9.5)$. The difference between the two compared means was not statistically significant $(P=0.897)$. Similarly, the investigated groups did not differ in terms of the time since the last menstrual period $(P=0.514$ and $P=0.735$, respectively), BMI $(P=0.285)$, and the number of pregnancies and deliveries in the patients' lifetimes $(P=0.260$ and $\mathrm{P}=0.244$, respectively).

Statistically significant differences between the investigated groups were observed in the concentration of HE4 ( $P=0.001)$, with medians of $96.7 \mathrm{pM}$ and $46.1 \mathrm{pM}$ in the group of women with endometrial cancer and in the healthy women, respectively. The obtained results are shown in Figure 1.

An analysis of the concentration of the tumour markers CA125 and HE4 in the blood serum of women with endometrial cancer and women from the control group was conducted. The median CA125 concentration was $5.8 \mathrm{U} / \mathrm{ml}$ in the group of women with endometrial cancer and $5.2 \mathrm{U} / \mathrm{ml}$ in the group of women without cancer. The difference between the compared values was not statistically significant $(P=0.661)$ (Fig. 2).

Among the 180 patients operated due to endometrial cancer, $140(77.8 \%)$ were classified to stage 1 of clinical advancement according to FIGO (2009), 24 (13.3\%) were classified to stage 2 , and 16 were classified to stages 3 and 4 (eight per stage, 4.4\%). No statistically significant differences in the concentration of the tumour markers were observed between the group

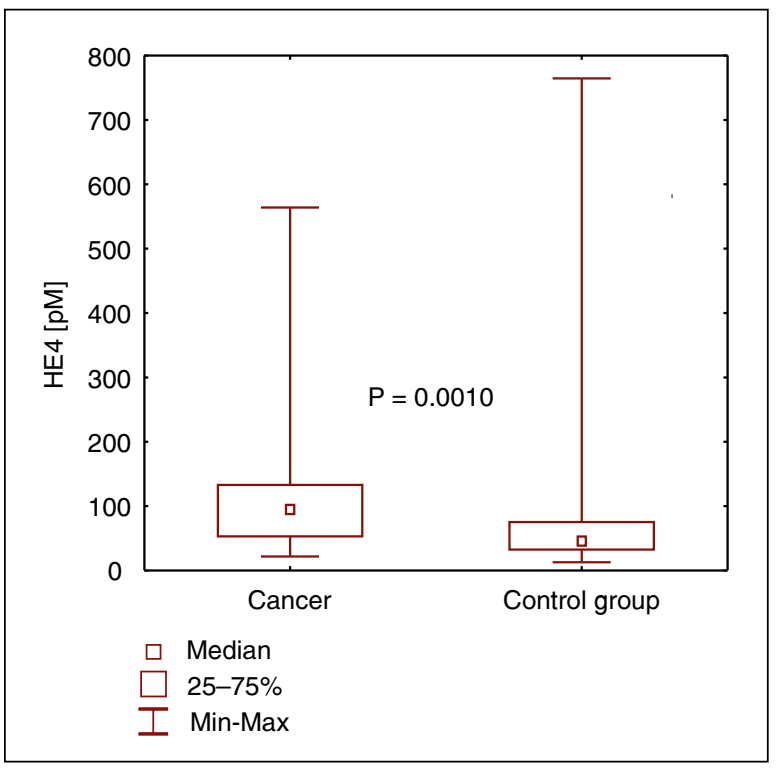

Figure 1. Serum concentrations of HE4 in endometrial cancer patients and in controls 
of women with stage 1 endometrial cancer and the groups with further stages of the disease according to FIGO (Tab. 2).

It was found that the blood serum concentration of HE4 was significantly higher in the patients with stage 1 endometrial cancer compared to the group of

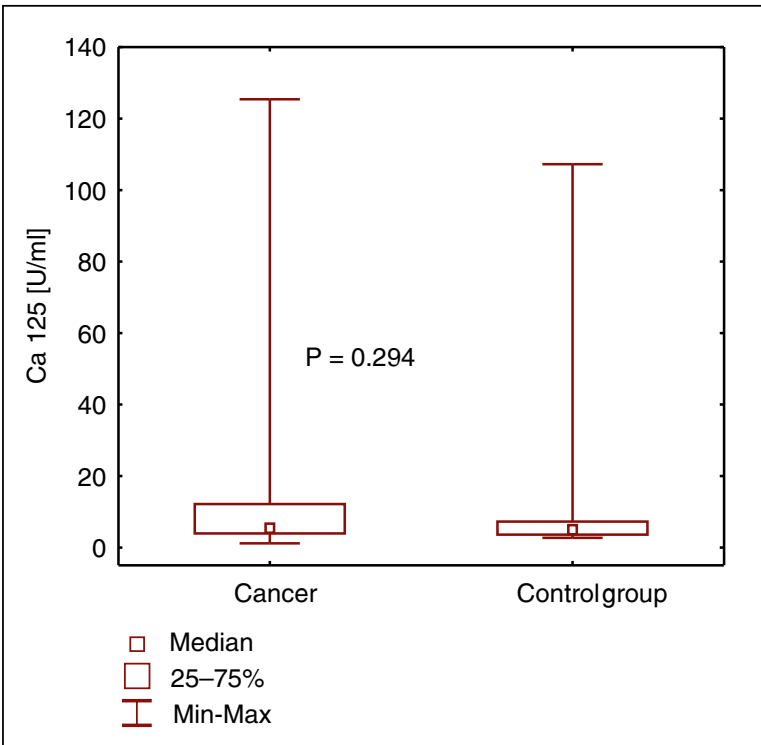

Figure 2. Serum concentrations of CA 125 in endometrial cancer patients and in controls healthy women $(P=0.007)$, with medians of $88.37 \mathrm{pM}$ and $46.14 \mathrm{pM}$, respectively (Tab. 2).

The statistical significance of CA125 markers $(P=0.795)$ and HE4 $(P=0.873)$ was not found depending on the incidence of type I and type II endometrial carcinoma in groups $\mathrm{N}=164, \mathrm{~N}=16$, respectively

Tumour marker concentration stratified according to the histopathological grade of endometrial cancer to two groups $\mathrm{G} 1(\mathrm{~N}=36)$ and $\mathrm{G} 2 / \mathrm{G} 3(\mathrm{~N}=136)$. In statistical analysis of CA125 marker, the P-value was near-borderline significance $(P=0.101)$. Analysis of HE4 showed no statistical significance $(P=0.363)$.

An analysis of the effectiveness of endometrial cancer detection depending on the concentration of the tested marker was conducted. The adopted cut-off values were based on the reference values of the diagnostic tests from Demeditec Diagnostics GmbH (for CA125) and FUJIREBIO Diagnostics, Inc. (for HE4). No statistical significance was found in the results of the assessment of cancer detection effectiveness relative to the reference values for CA125 and HE4. The results are shown in Table 3 and 4.

In the presented study, no correlation was observed between the concentration of CA125/HE4 at $95 \% \mathrm{Cl}$ and the effectiveness of endometrial cancer detection ( $P=0.652$ and $P=0.276$, respectively).

High specificity of tumour markers with clearly unsatisfactory sensitivity and low predictive value, positive and negative, causes the accuracy to be estimated at a concentration no greater than $60 \%$ (Tab. 5).

Table 2. Tumour marker concentration in patients with endometrial cancers representing FIGO stage I, higher stages of the FIGO classification, and in the controls

\begin{tabular}{|c|c|c|c|c|c|}
\hline \multirow[t]{2}{*}{ Markers } & \multirow{2}{*}{$\begin{array}{l}\text { Statistical } \\
\text { parameter }\end{array}$} & \multirow[b]{2}{*}{$\begin{array}{c}\text { Control group } \\
N=128\end{array}$} & \multirow[b]{2}{*}{$\begin{array}{c}\text { Endometrial } \\
\text { cancer group } \\
\mathbf{N}=180\end{array}$} & \multicolumn{2}{|c|}{ FIGO } \\
\hline & & & & $N=140$ & $\begin{array}{c}\text { II-IV } \\
N=40\end{array}$ \\
\hline $\begin{array}{l}\mathrm{CA} 125 \\
{[\mathrm{U} / \mathrm{ml}]}\end{array}$ & $\begin{array}{l}\text { Me } \\
\text { Q1 } \\
\text { Q3 }\end{array}$ & $\begin{array}{l}5.2 \\
3.4 \\
7.5\end{array}$ & $\begin{array}{c}5.8 \\
3.7 \\
12.4\end{array}$ & $\begin{array}{c}4.8 \\
2.7 \\
12.4\end{array}$ & $\begin{array}{c}8.1 \\
5.6 \\
13.6\end{array}$ \\
\hline $\begin{array}{l}\text { HE4 } \\
\text { [pM] }\end{array}$ & $\begin{array}{l}\text { Me } \\
\text { Q1 } \\
\text { Q3 }\end{array}$ & $\begin{array}{l}46.1 \\
31.2 \\
76.3\end{array}$ & $\begin{array}{c}96.7 \\
51.8 \\
134.2\end{array}$ & $\begin{array}{c}88.4 \\
44.6 \\
125.8\end{array}$ & $\begin{array}{c}122.5 \\
87.9 \\
211.6\end{array}$ \\
\hline
\end{tabular}

FIGO - The International Federation of Gynaecology and Obstetrics; Me - median; Q1 Q3 - quartile

Table 3. Endometrial cancer detection rates depending on a cut-off value for the CA125 test

\begin{tabular}{lccccc}
\hline Serum concentration & \multicolumn{3}{c}{ The occurrence of endometrial cancer } & \multirow{2}{*}{ Total } \\
\cline { 2 - 5 } CA125 & \multicolumn{3}{c}{ present } & absent & N \\
\cline { 2 - 5 } & $\mathbf{N}$ & $\%$ & 12 & $\%$ & 28 \\
\hline$>=29.6 \mathrm{U} / \mathrm{ml}$ & 16 & 9 & 116 & 91 & 280 \\
$<29.6 \mathrm{U} / \mathrm{ml}$ & 164 & 91 & 128 & 100 & 308 \\
Total & 180 & 100 & & & \\
$\mathrm{p}=0.742$ & & & &
\end{tabular}


Table 4. Endometrial cancer detection rates depending on a cut-off value for the HE4 test

\begin{tabular}{|c|c|c|c|c|c|}
\hline \multirow{3}{*}{$\begin{array}{l}\text { Serum concentration } \\
\text { HE4 }\end{array}$} & \multicolumn{4}{|c|}{ The occurrence of endometrial cancer } & \multirow{3}{*}{$\begin{array}{c}\text { Total } \\
\mathbf{N}\end{array}$} \\
\hline & \multicolumn{2}{|c|}{ present } & \multicolumn{2}{|c|}{ absent } & \\
\hline & $\mathbf{N}$ & $\%$ & $\mathbf{N}$ & $\%$ & \\
\hline$>=150 \mathrm{pM}$ & 40 & 22 & 16 & 13 & 56 \\
\hline$<150 \mathrm{pM}$ & 140 & 78 & 112 & 88 & 252 \\
\hline Total & 180 & 100 & 128 & 100 & 308 \\
\hline$p=0.276$ & & & & & \\
\hline
\end{tabular}

Table 5. Summary of diagnostic accuracy of the analysed tumour markers

\begin{tabular}{|c|c|c|c|c|c|c|}
\hline Markers & Criterion & Sensitivity & Specificity & PPV & NPV & Accuracy \\
\hline \multirow[t]{2}{*}{ CA125 } & reference value $(29.6 \mathrm{U} / \mathrm{ml})$ & $8.89 \%$ & $90.63 \%$ & $57.14 \%$ & $41.43 \%$ & $42.86 \%$ \\
\hline & $95 \% \mathrm{Cl}(18.26 \mathrm{U} / \mathrm{ml})$ & $15.56 \%$ & $90.63 \%$ & $70.00 \%$ & $43.28 \%$ & $46.75 \%$ \\
\hline \multirow[t]{2}{*}{ HE4 } & reference value $(150 \mathrm{pM})$ & $22.22 \%$ & $87.50 \%$ & $71.43 \%$ & $44.44 \%$ & $49.35 \%$ \\
\hline & $95 \% \mathrm{Cl}(141.62 \mathrm{pM})$ & $22.22 \%$ & $87.50 \%$ & $71.43 \%$ & $44.44 \%$ & $49.35 \%$ \\
\hline
\end{tabular}

NPV — negative predictive value; PPV — positive predictive value

CA125 offers the best diagnostic usefulness within the $95 \% \mathrm{Cl}$, reaching $90.63 \%$ specificity and $70 \%$ positive predictive value, with $15.56 \%$ sensitivity and a negative predictive value of $43.28 \%$. The diagnostic accuracy for this cut-off value was $46.75 \%$.

The reference value for the HE4 test within the previously established $95 \% \mathrm{Cl}$ allows the detection of endometrial cancer with $22.22 \%$ sensitivity and $87.5 \%$ specificity, with a satisfactory positive predictive value of $71.43 \%$. The diagnostic accuracy of this tumour marker is up to $49.35 \%$.

A ROC curve analysis was performed in order to assess the diagnostic value of the tumour markers. Assessing the blood serum HE4 concentration allowed determination of the presence of endometrial cancer with $66.7 \%$ sensitivity and $78.1 \%$ specificity, with extinction values above $80.487 \mathrm{pM}$. The area under the ROC curve for HE4 was 0.721 , which indicated a good diagnostic value (Fig. 3).

The area under the ROC curve for CA125 indicated a lack of discriminative value of this parameter as a prognostic factor in the diagnostics of endometrial cancer (Fig. 4).

In a summary of the diagnostic value of the investigated markers based on the AUC of the ROC curves, HE4 obtained the highest sensitivity at $66.7 \%$ with $78.1 \%$ specificity and a satisfactory positive predictive value (PPV).

When comparing the logistic regression models in terms of the ability to detect endometrial cancer

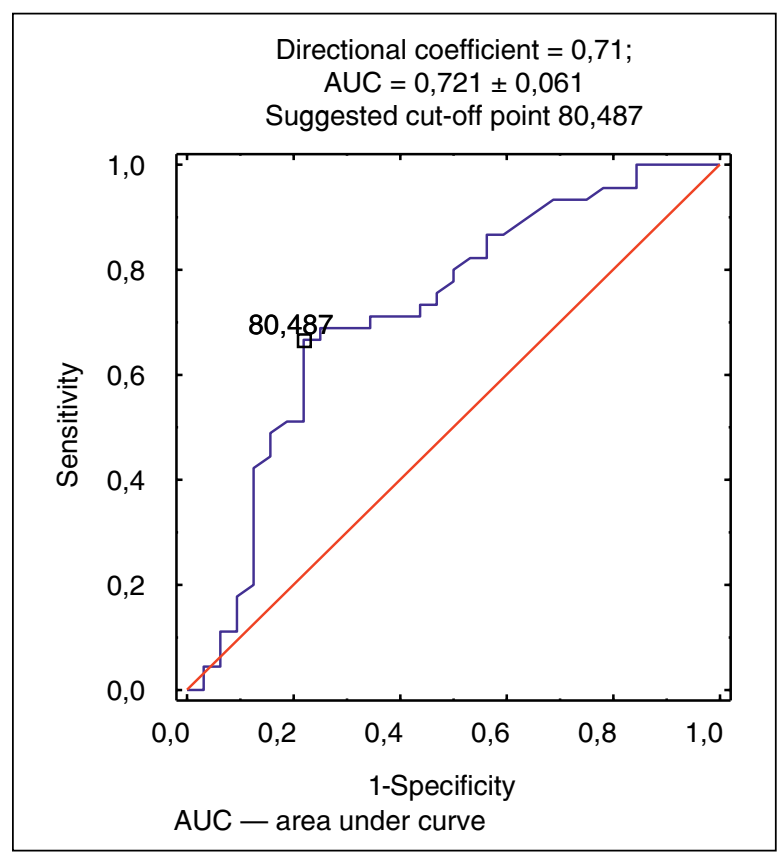

Figure 3. Area under the receiver operating characteristic (ROC-AUC) curve for HE-4 as a diagnostic marker of endometrial cancer

by the investigated tumour markers, the optimal model in the diagnostics of endometrial cancer from a statistical point of view is model $2(P=0.0001)$ (Tab. 6). 


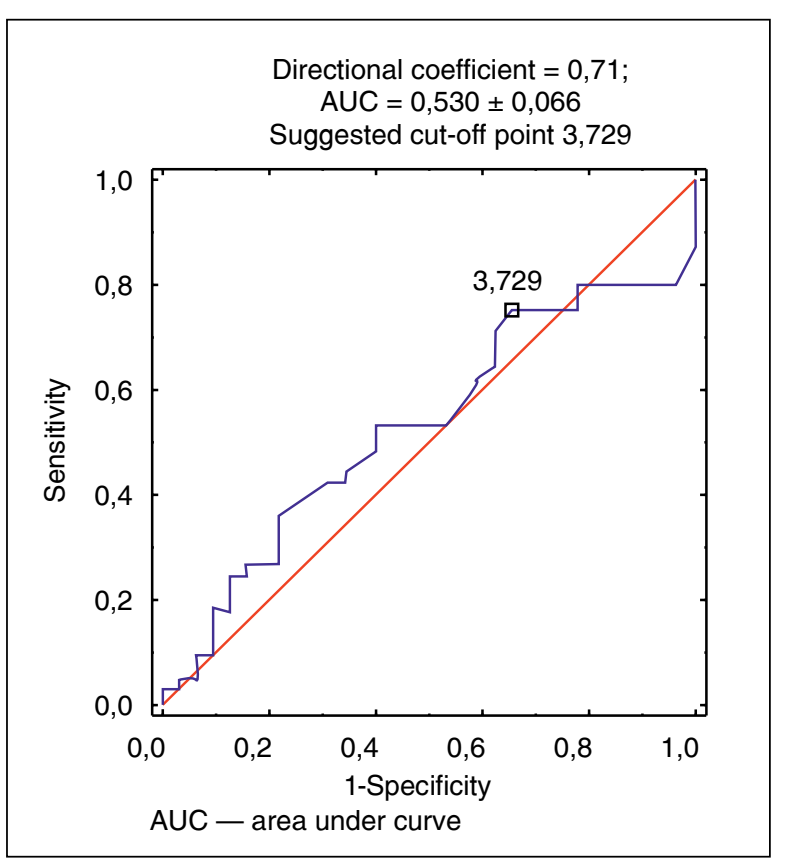

Figure 4. Area under the receiver operating characteristic (ROC-AUC) curve for CA 125 as a diagnostic marker of endometrial cancer

Table 6. P-value from the analysis of logistic regression models that describe the ability to detect cancer by the analysed markers. Dichotomous independent variables are associated with the cut-off points determined during analysis of the ROC curves

\begin{tabular}{lccc}
\hline & $\begin{array}{c}\mathbf{C h i}^{2} \\
\mathbf{P}\end{array}$ & $\begin{array}{c}\text { Marker 1 } \\
\mathbf{P}\end{array}$ & $\begin{array}{c}\text { Marker 2 } \\
\mathbf{P}\end{array}$ \\
\hline Model 1 & 0.3437 & $\mathrm{CA} 125$ & \\
& & 0.3466 & \\
Model 2 & $0.0001^{*}$ & $\mathrm{HE} 4$ & \\
& & $0.0004^{*}$ & \\
Model 3 & $0.0003^{*}$ & $\mathrm{CA} 125$ & $\mathrm{HE} 4$ \\
& & 0.5545 & $0.0005^{\star}$ \\
\end{tabular}

$\star P<0.05$

\section{Discussion}

Endometrial cancer produces symptoms at the early stages of clinical advancement, which improves the prognosis. However, due to the lack of a safe, noninvasive screening method for detecting this cancer, it is reasonable to search for new substances, particularly useful for patients with increased risk, including people with severe obesity and diabetes, Lynch syndrome, PTEN gene defects, or women treated with tamoxifen. Quantification of tumour markers in the blood serum of women seems to be acceptable as a potential diagnostic method for detecting endometrial cancer due to the low cost of the method, the possibility of repeating the test at any interval, as well as the safety and diagnostic usefulness of the method. The quantitative nature of the obtained result, although not conclusive in the diagnostics of the disease, allows the clinical assessment to be more objective.

In this study, an analysis of the concentration of tumour markers was conducted using the blood serum of female patients with endometrial cancer in comparison with the control group. The median HE4 concentration was higher in the cancer patients to a statistically significant degree $(P=0.001)$, while CA125 did not demonstrate such a correlation $(P=0.661)$. The HE4 concentration in the cancer group and in the healthy women were 96.7 and $46.1 \mathrm{pM}$, respectively. Similar values were reported by Moore, R.G. et al. (71.5 and 35.4 pM, respectively), as well as by Znang, A.M. et al. [13-14]. The authors confirmed the presence of higher concentrations of HE4 in cancer patients as well, using another diagnostic method [11-13, 15-16].

There are also many reports on the increased concentration of CA125 in the blood serum of women with endometrial cancer. According to some authors, only $10-30 \%$ of women with endometrial cancer have increased concentration of this glycoprotein in the blood, which is confirmed by our results [17-18]. However, many publications report significant differences in the concentration of CA125 in the blood serum of women with endometrial cancer compared to healthy individuals [19-22]. In this study, the median CA125 concentration in the blood serum of cancer patients was only $5.8 \mathrm{U} / \mathrm{ml}$ and was virtually comparable to the median concentration of CA125 in the blood serum of healthy individuals $(5.2 \mathrm{U} / \mathrm{ml})$. The cause of such low values of the CA125 concentration in the blood serum of the investigated group may be, e.g., the prevalence of women at an early stage of disease advancement. This was confirmed by Powell, J.L. et al., who obtained the correct values of the blood CA125 concentration in approx. $87.7 \%$ of the cases of FIGO stage 1 and 2 disease [22]. On the other hand, Nicklin, J. et al. obtained medians of approx. $14 \mathrm{U} / \mathrm{ml}$ and observed statistically significant differences in the CA125 concentration in the blood serum of women with endometrial cancer and healthy individuals [23]. The findings of Powell, J.L. and the authors of this study are confirmed in a study conducted by Bignotti, E., who did not observe any statistically significant differences in the group of patients with stage 1 and 2 of clinical advancement and the G1 degree of histopathological differentiation in comparison with healthy individuals [15]. The results demonstrate the limited usefulness of the antigen CA125 in detecting endometrial cancer.

An interesting issue considered in this study is the evaluation of the concentration of the investigated mark- 
ers in relation to the stage of clinical advancement according to FIGO. The obtained statistical differences in the concentration of HE4 in the blood serum of healthy women and women with FIGO stage 1 endometrial cancer suggest possible usefulness of this marker in screening tests $(P=0.007)$. Human Epididymis Protein 4 , as the only one of the investigated markers, demonstrated a different concentration in the control group and in patients with FIGO stage 1 cancer. This correlation has also been described by Moore, R.G. et al. and Bignotti, E. [13, 15]. However, these results were not confirmed by Kalogera, $E$. et al. $(P=0.49)$ [12]. Differences in the published studies suggest the need for further research on this topic.

Some authors have reported a statistically significant difference between the concentration of HE4 in the blood serum of patients with FIGO stage 1 endometrial cancer and those with further stages of the disease [12, 15]. In this study, the analysis of the concentration of HE4 was performed either at FIGO stage 1 or at further stages [2-4] of clinical advancement. Due to the small size of the groups with further stages of clinical advancement, patients with FIGO stages 2-4 were assessed together. As opposed to other authors, we observed no statistically significant difference in the marker concentration ( $P=0.120)$; however, the median HE4 concentration at further stages of clinical advancement was higher (122.46 pM) compared to stage 1 according to FIGO (median $=88.37 \mathrm{pM}$ ).

The differences in the blood serum concentration of CA125 in women with FIGO stage 1 and further stages of clinical advancement were close to statistical significance $(P=0.062)$. The presented results are consistent with reports by other researchers, which confirm the correlation of the CA125 concentration with increasing degree of clinical advancement [15, 18, 22, 24].

In the analysis of the concentrations of the investigated markers in relation to the aetiopathogenetic type of endometrial cancer, the median marker concentration values established in the blood serum of women with either type I or type II cancer were higher than those found in healthy individuals. No statistically significant differences with respect to the blood serum concentration of CA125 and HE4 were observed between women with type I and type II endometrial cancer $(P=0.795$; $P=0.873)$. However, the median CA125 concentration was higher in patients with type II disease.

The concentration of HE4 shows an opposite relationship, in which the median concentration of this marker in oestrogen-dependent cancer is higher than in the hormone-independent type. However, it should be pointed out that the group of patients with type II cancer in this study was small, which justifies the need for continuing the research in a larger group of patients. Our results of the HE4 quantification in patients with type I and II endometrial cancer are confirmed in the study published by Kalogera et al. [12]. As for the other markers, the correlation of higher marker concentrations with type II cancer allowed the identification of patients with poor prognosis, requiring constant monitoring for a possible relapse of the disease and a plan for more aggressive treatment.

The comparison of the marker concentration in relation to the degree of histopathological differentiation of endometrial cancer revealed no statistically significant differences. A tendency of the CA125 and HE4 concentration to reach higher values in the blood serum of patients with G2 and G3 cancer was demonstrated, with CA125 being nearest to statistical significance.

A similar correlation was shown in the studies by Powell, J.L. et al. and Dvalishvili, I. et al. [22, 25]. Differences in the concentration of HE4 depending on the degree of histopathological differentiation were observed by Bignotti, E. et al. [15].

For a reliable assessment of the diagnostic usefulness of the investigated tumour markers, the diagnostic sensitivity and specificity were established in relation to the different cut-off values for a given marker.

The first assessment regarded the predictive value and utilised the suggested upper limit of the reference values $(>95 \% \mathrm{Cl}$ ) used in the study of diagnostic tests based on the ELISA method. On the basis of the authors' own observations, the $95 \% \mathrm{Cl}$ value was established in the investigated group of women, and the effectiveness of the investigated tumour markers in endometrial cancer detection was assessed in relation to the results obtained. The study estimated the predictive capacity of CA125 with a sensitivity as low as $8.89 \%$ and a specificity of $90.63 \%$, with the cut-off value based on the reference value upper limit from the CA19-9 ELISA test by Demeditec Diagnostics GmbH, which was $\geq 29.6 \mathrm{U} / \mathrm{ml}$. No correlation with cancer occurrence was observed above this value $(P=0.742)$. The low positive and negative predictive value resulted in an accuracy estimate of only $42.86 \%$. A slightly higher accuracy was obtained for the $\geq 95 \% \mathrm{Cl}$ established in the authors' own study. For concentrations $\geq 18.26 \mathrm{U} / \mathrm{ml}$, the accuracy was $46.75 \%$. The low sensitivity and NPV values cause this marker to be ineffective in the diagnostics of endometrial cancer. Despite the unsatisfactory results obtained in the assessment of diagnostic usefulness, CA125 is used in clinical practice for monitoring patients with a high risk of relapse of the disease. It is also used for planning the extent of surgery. Values $\geq 65 \mathrm{U} / \mathrm{ml}$ strongly correlate with the spread of the disease outside the uterus [26].

Very disappointing results were obtained in the assessment of the effectiveness of endometrial cancer detection with HE4. The marker considered as the best marker in the diagnostics and monitoring of the treat- 
ment of endometrial cancer obtained only $49.35 \%$ accuracy. The obtained sensitivity of $22.22 \%$ is clearly unsatisfactory in the assessment of the test marker, while the specificity of $87.5 \%$ is lower compared to CA125.

The lack of established standards for HE4 prevented the assessment of the marker's usefulness in detecting endometrial cancer in relation to the cut-off value adopted for the population of healthy women. The attempts to establish the reference values performed to date have produced divergent results and have not taken into account the influence of many factors. A recent study by Bolstad, $\mathrm{N}$. et al. involving material from 1591 women and men presents the correlation between the HE4 concentration and smoking status and age. The cut-off values cited by the authors are significantly lower than the reference value from the HE4 EIA test by FUJIREBIO Diagnostics, Inc. ( 150 pM), as well as the values proposed by Molina, R. et al. (> $130 \mathrm{pM}$ ) and Lenhard M. et al. [27-29].

Due to the unsatisfactory results obtained in the assessment of the diagnostic usefulness of the investigated tumour markers, and in order to further compare them, ROC curves were established on the basis of the extinction value distribution for each parameter. Cut-off values characterised by the highest diagnostic value were identified, and the assessment of the area under the curve (ROC-AUC) was performed in order to estimate the discriminative value of each parameter.

The cut-off value for HE4 was established at $80.487 \mathrm{pM}$, which allowed the detection of endometrial cancer with $66.7 \%$ sensitivity and $78.1 \%$ specificity above the established extinction value. The positive predictive value of $81 \%$ allowed the detection of the disease based on a positive test result above the established cut-off value. When calculating the area under the ROC curve for HE4, a good discriminative value of this parameter was observed (ROC-AUC = 0.721). Moor, R.G. et al. and Kalogera, E. et al. obtained similar results of 0.79 and 0.67 , respectively [12-13]. The differences between the individual studies may be due to the differences in the distribution of stages of clinical advancement in the investigated groups of patients.

The values obtained with CA125 allowed confirmation of the presence of a cancerous disease with $75.6 \%$ sensitivity and a very low specificity of $34.4 \%$. The cut-off value $(3.729 \mathrm{U} / \mathrm{ml})$ established in this study differed significantly from the results obtained by Kim, B.W. et al., who reported a value of $18.7 \mathrm{U} / \mathrm{ml}$. Moreover, the authors obtained a fairly good discriminative capacity for this parameter because the area under the ROC curve was 0.689 with $49.3 \%$ sensitivity and $83.1 \%$ specificity [30]. The observed differences may arise from the different distribution of the clinical status of the patients included in the study.
In the present study, an analysis of the correlation between the concentration of tumour markers and the occurrence of endometrial cancer was also performed. For this purpose, three logistic regression models with different combinations of the tested substances were established and assessed. Model 3, which took into account the influence of CA125 and HE4 on the detection of cancer, was characterised by a lower predictive capacity than the single-component model $1(P=0.0003$ vs. 0.0001$)$, which confirms the lack of any advantage of combined CA125 and HE4 determination in the diagnostics of endometrial cancer. Other researchers have also attempted similar analyses and obtained data suggesting an advantage of combined CA125 and HE4 determination over the assessment of single markers [13].

To conclude, the obtained results confirm that HE4 is the most sensitive and specific marker for the early detection of patients with endometrial cancer, as compared with CA125, which is commonly used in the monitoring of patients with endometrial cancer. However, the numerous discrepancies that are still observed in the assessment of the usefulness of the tumour markers indicate the need for further research involving larger groups and careful conclusions with reference to the established cut-off values for the healthy population.

\section{References}

1. Ballehaninna UK, Chamberlain RS. The clinical utility of serum CA 19-9 in the diagnosis, prognosis and management of pancreatic adenocarcinoma: An evidence based appraisal. J Gastrointest Oncol. 2012; 3(2): 105-119, doi: 10.3978/j.issn.2078-6891.2011.021, indexed in Pubmed: 22811878.

2. Scurry J, Brand A, Sheehan P, et al. High-grade endometrial carcinoma in secretory endometrium in young women: a report of five cases. Gynecol Oncol. 1996; 60(2): 224-227, doi: 10.1006/gyno.1996.0029, indexed in Pubmed: 8631542.

3. Kaku T, Matsuo K, Tsukamoto N, et al. Endometrial carcinoma in women aged 40 years or younger: a Japanese experience. Int J Gynecol Cancer. 1993; 3(3): 147-153, doi: 10.1046/j.1525-1438.1993.030301 47.x, indexed in Pubmed: 11578335.

4. Ueda SM, Kapp DS, Cheung MK, et al. Trends in demographic and clinical characteristics in women diagnosed with corpus cancer and their potential impact on the increasing number of deaths. Am J Obstet Gynecol. 2008; 198(2): 218.e1-218.e6, doi: 10.1016/j. ajog.2007.08.075, indexed in Pubmed: 18226630.

5. Koss LG, Schreiber K, Oberlander SG, et al. Detection of endometrial carcinoma and hyperplasia in asymptomatic women. Obstet Gynecol. 1984; 64(1): 1-11, indexed in Pubmed: 6738931.

6. Wright TC, Massad LS, Dunton CJ, et al. 2006 American Society for Colposcopy and Cervical Pathology-sponsored Consensus Conference. 2006 consensus guidelines for the management of women with abnormal cervical cancer screening tests. Am J Obstet Gynecol. 2007; 197(4): 346-355, doi: 10.1016/j.ajog.2007.07.047, indexed in Pubmed: 17904957.

7. Ragni N, Ferrero S, Prefumo F, et al. The association between p53 expression, stage and histological features in endometrial cancer. Eur J Obstet Gynecol Reprod Biol. 2005; 123(1): 111-116, doi: 10.1016/j. ejogrb.2005.03.018, indexed in Pubmed: 15894417.

8. Keys HM, Roberts JA, Brunetto VL, et al. Gynecologic Oncology Group. A phase III trial of surgery with or without adjunctive external pelvic radiation therapy in intermediate risk endometrial adenocarcinoma: a Gynecologic Oncology Group study. Gynecol Oncol. 2004; 92(3): 744-751, doi: 10.1016/j.ygyno.2003.11.048, indexed in Pubmed: 14984936. 
9. Creutzberg CL, van Putten WLJ, Koper PC, et al. PORTEC Study Group. Survival after relapse in patients with endometrial cancer: results from a randomized trial. Gynecol Oncol. 2003; 89(2): 201-209 doi: 10.1016/s0090-8258(03)00126-4, indexed in Pubmed: 12713981.

10. Fung-Kee-Fung M, Dodge J, Elit L, et al. Cancer Care Ontario Program in Evidence-based Care Gynecology Cancer Disease Site Group. Follow-up after primary therapy for endometrial cancer: a systematic review. Gynecol Oncol. 2006; 101(3): 520-529, doi: 10.1016/j. ygyno.2006.02.011, indexed in Pubmed: 16556457

11. Galgano MT, Hampton GM, Frierson HF. Comprehensive analysis of HE4 expression in normal and malignant human tissues. Mod Pathol. 2006; 19(6): 847-853, doi: 10.1038/modpathol.3800612, indexed in Pubmed: 16607372.

12. Kalogera E, Scholler N, Powless $C$, et al. Correlation of serum HE4 with tumor size and myometrial invasion in endometrial cancer. Gynecol Oncol. 2012; 124(2): 270-275, doi: 10.1016/j.ygyno.2011.10.025, indexed in Pubmed: 22037318.

13. Moore RG, Brown AK, Miller MC, et al. Utility of a novel serum tumor biomarker HE4 in patients with endometrioid adenocarcinoma of the uterus. Gynecol Oncol. 2008; 110(2): 196-201, doi: 10.1016/j. ygyno.2008.04.002, indexed in Pubmed: 18495222.

14. Zhang Am, Zhang P. [Clinical value of combined detection of serum human epididymal secretory protein $\mathrm{E} 4$ and $\mathrm{CA}(125)$ in the diagnosis of endometrial carcinoma]. Zhonghua Fu Chan Ke Za Zhi. 2012; 47(2): 125-128, indexed in Pubmed: 22455745

15. Bignotti E, Ragnoli M, Zanotti L, et al. Diagnostic and prognostic impact of serum HE4 detection in endometrial carcinoma patients. $\mathrm{Br} J$ Cancer. 2011; 104(9): 1418-1425, doi: 10.1038/bjc.2011.109, indexed in Pubmed: 21468050.

16. Mutz-Dehbalaie I, Egle D, Fessler S, et al. HE4 is an independent prognostic marker in endometrial cancer patients. Gynecol Oncol. 2012; 126(2): 186-191, doi: 10.1016/j.ygyno.2012.04.022, indexed in Pubmed: 22525819.

17. Li J, Dowdy S, Tipton T, et al. HE4 as a biomarker for ovarian and endometrial cancer management. Expert Rev Mol Diagn. 2009; 9(6): 555-566, doi: 10.1586/erm.09.39, indexed in Pubmed: 19732003.

18. Sebastianelli A, Renaud MC, Grégoire J, et al. Preoperative CA 125 tumour marker in endometrial cancer: correlation with advanced stage disease. J Obstet Gynaecol Can. 2010; 32(9): 856-860, doi: 10.1016/S1701-2163(16)34657-6, indexed in Pubmed: 21050518.

19. Ginath S, Menczer J, Fintsi Y, et al. Tissue and serum CA125 expression in endometrial cancer. Int J Gynecol Cancer. 2002; 12(4): 372-375, doi: 10.1046/j.1525-1438.2002.01007.x, indexed in Pubmed: 12144685
20. Gadducci A, Cosio S, Carpi A, et al. Serum tumor markers in the management of ovarian, endometrial and cervical cancer. Biomed Pharmacother. 2004; 58(1): 24-38, doi: 10.1016/j.biopha.2003.11.003, indexed in Pubmed: 14739059.

21. Kim HS, Park CY, Lee JM et al. Evaluation of serum CA-125 levels for preoperative counseling in endometrioid endometrial cancer a multi-center study. Gynecol Oncol. 2010; 118(3): 283-288, doi: 10.1016/.ygyno.2010.04.018, indexed in Pubmed: 20541245

22. Powell JL, Hill KA, Shiro BC, et al. Preoperative serum CA-125 levels in treating endometrial cancer. J Reprod Med. 2005; 50(8): 585-590, indexed in Pubmed: 16220763.

23. Nicklin J, Janda M, Gebski V, et al. LACE Trial Investigators. The utility of serum CA-125 in predicting extra-uterine disease in apparent early-stage endometrial cancer. Int J Cancer. 2012; 131(4): 885-890, doi: 10.1002/ijc.26433, indexed in Pubmed: 21918977.

24. Cho H, Kang ES, Kim YT, et al. Diagnostic and prognostic impact of osteopontin expression in endometrial cancer. Cancer Invest. 2009. 27(3): 313-323, doi: 10.1080/07357900802375738, indexed in Pubmed: 19194826

25. Dvalishvili I, Charkviani L, Turashvili G, et al. Clinical characteristics of prognostic factors in uterine endometrioid adenocarcinoma of various grade. Georgian Med News. 2006(132): 24-27, indexed in Pubmed: 16636372

26. Dotters DJ. Preoperative CA 125 in endometrial cancer: is it useful? Am J Obstet Gynecol. 2000; 182(6): 1328-1334, doi: 10.1067/mob.2000.106251, indexed in Pubmed: 10871446.

27. Molina R, Escudero JM, Augé JM et al. HE4 a novel tumour marker for ovarian cancer: comparison with CA 125 and ROMA algorithm in patients with gynaecological diseases. Tumour Biol. 2011; 32(6): 1087-1095, doi: 10.1007/s13277-011-0204-3, indexed in Pubmed: 21863264.

28. Bolstad N, Øijordsbakken M, Nustad K, et al. Human epididymis protein 4 reference limits and natural variation in a Nordic reference population. Tumour Biol. 2012; 33(1): 141-148, doi: 10.1007/s13277011-0256-4, indexed in Pubmed: 22105734

29. Lenhard M, Stieber P, Hertlein L, et al. The diagnostic accuracy of two human epididymis protein 4 (HE4) testing systems in combination with CA125 in the differential diagnosis of ovarian masses. Clin Chem Lab Med. 2011; 49(12): 2081-2088, doi: 10.1515/CCLM.2011.709, indexed in Pubmed: 21923475.

30. Kim BoW, Jeon YE, $\mathrm{Cho} \mathrm{H}$, et al. Pre-treatment diagnosis of endometrial cancer through a combination of CA125 and multiplication of neutrophil and monocyte. J Obstet Gynaecol Res. 2012; 38(1): 48-56, doi 10.1111/j.1447-0756.2011.01694 x, indexed in Pubmed: 22142582. 